\title{
Increased Rate of Capping of Concanavalin A Receptors during Early Xenopus Development Is Related to Changes in Protein and Lipid Mobility
}

\author{
M. Gadenne,* E. J. J. van Zoelen, $†$ R. Tencer,* and S. W. De LaAT $\dagger^{+1}$ \\ *Université libre de Bruxelles, Département de Biologie Moléculaire, 67, mue des Chevaux, 1640 Rhode-St-Genèse, Belgium, and \\ $\nmid$ Hubrecht Laboratory, International Embryological Institute, Uppsalalaan 8, 3584 CT Utrecht, The Netherlands
}

Received October 7, 1983; accepted in revised form March 20, 1984

\begin{abstract}
The mobility characteristics of plasma membrane constituents were studied in dissociated cells from embryos of Xenopus laevis at various stages of development from early blastula until neurulation. An increased rate of fluorescein isothiocyanate-concanavalin A induced patching and capping of Con A-binding proteins during this period of development was correlated with a threefold increase in the lateral mobility of the receptor molecules, as determined by the fluorescent photobleaching recovery (FPR) method, the major change occurring at the onset of gastrulation. Using the same method, it was demonstrated that the lateral mobility of plasma membrane lipids increases twofold during this period of development. The major change being detectable, however, at the late blastula stage. This is in coincidence with the initiation of cell motility in dissociated Xenopus embryo cells. It is concluded that the lateral mobility of membrane proteins and lipids increases significantly during early Xenopus development, but are at least in part subject to different control mechanisms. The results suggest that the initiation of morphogenetic movements is related to changes in the dynamic properties of plasma membrane constituents.
\end{abstract}

\section{INTRODUCTION}

At the onset of gastrulation movements, several changes in cellular behavior take place in the amphibian embryo. In particular, dissociated cells of the embryo show an increase in cellular adhesiveness (Johnson, 1969, $1970,1972)$ and cell surface charge, as determined by electrophoretic mobility (MacMurdo et al, 1970; Shaeffer et al, 1973). Furthermore, these cells become much more actively motile at this stage of development. It is most likely that these changes are related to modifications of cell surface properties.

Holtfreter (1946) was the first to observe that dissociated cells from amphibian embryos undergo a particular type of movement, known as the circus movement. This process involves the periodic extension of a hyaline lobopodium, which is propagated around the cell body. In the embryo of Xenopus laevis the ability of cells to extend lobopodia does not appear before the blastula stage and the percentage of cells showing lobopodial activity is very low before the late blastula stage. However, cell motility, as expressed by lobopodium formation, increases considerably thoughout gastrulation (Satoh et al, 1976). It is not clear to what extent the lobopodia observed in dissociated cells really play a functional role in driving cells toward orientated migration. Their presence may be indicative, however,

\footnotetext{
${ }^{1}$ To whom correspondence should be addressed.
}

of the competence of cells in the intact embryo to form lamellipodia or filopodia, which seem directly involved in the process of cell migration (Nakatsuji, 1976).

The studies of Tickle and Trinkaus $(1973,1977)$ on Fundulus embryos have shown a correlation between cell motility and the deformability of the cell surface. Since cellular deformability is largely controlled by plasma membrane fluidity, this suggests that changes in cellular movement may correlate with changes in membrane fluidity. Johnson and Smith (1977) have shown that binding of a fluorescently labeled lectin (concanavalin A) to dissociated cells of the $X$ laevis embryo gives rise to cap formation during a 30 -min treatment at gastrula stage, whereas no cap was observed at blastula stage. Since cap formation requires the lateral mobility of membrane proteins in the lipid matrix, Johnson and Smith (1977) have proposed that a modulation of plasma membrane fluidity may occur at the transition period from blastula to gastrula stage.

In the present study, we have tested the above hypothesis directly by measuring the lateral mobility characteristics of plasma membrane lipids and proteins in dissociated cells of $X$. laevis embryos at various developmental stages by means of the fluorescence photobleaching recovery (FPR) technique (for recent reviews on this technique, see Cherry, 1979; Edidin, 1981; Peters, 1981). Both the lateral diffusion coefficient of membrane lipids, as determined after incorporation 
of the fluorescent lipid analogue 5-( $N$-hexadecanoyl)aminofluorescein (HEDAF), and that of the membrane receptor for concanavalin A show a significant, gradual increase during development. No significant differences in lipid lateral mobility were observed at any developmental stage between cells isolated from the various germ layers. In parallel with the FPR measurements, we have followed the capping rate of concanavalin A on dissociated cells of Xenopus embryos from the morula to the early neurula stage. A direct relation between the rate of cap formation and the lateral diffusion coefficient of membrane lipids and proteins was observed.

\section{MATERIALS AND METHODS}

\section{Embryos}

Fertilized eggs of $X$ laevis were obtained from artificially induced mating of adults. Males and females were injected the day before with gonadotropic hormone. Embryos were dejellied by treatment with $0.14 M$ 2-mercaptoethanol according to a modification of the method of Wolf (1974) in Niu and Twitty solution (NTS) at $\mathrm{pH} 9.0$ (Niu and Twitty, 1953). Dejellied embryos were washed extensively with fresh NTS.

After removing the vitelline membrane with watchmaker's forceps, embryos were allowed to dissociate in $\mathrm{Ca}^{2+}, \mathrm{Mg}^{2+}$-free NTS containing $17 \mathrm{mM}$ citrate. After dissociation, the citrate solution was replaced by $\mathrm{Ca}^{2+}$, $\mathrm{Mg}^{2+}$-containing NTS.

Embryos were dissected to collect fragments from the three germ layers in the following way: at the blastula stage, fragments were isolated with a hair loop from the presumptive ventral ectoderm, dorsal mesoderm, and vegetative endoderm. At early neurula stages fragments were dissected from the presumptive neuroectoderm, chordomesoderm, and endoderm. Dissected fragments were allowed to remain undisturbed in NTS for a few minutes, before proceeding to dissociation in citrate solution as described above. Stage numbers of the embryo are given according to Nieuwkoop and Faber (1967).

\section{Fluorescent Labeling of Cells}

Dissociated cells at the desired stage of development (blastula, gastrula, or neurula stages) were incubated in the presence of fluorescein isothiocyanate-conjugated concanavalin-A (FITC-Con A) at $50 \mu \mathrm{g} / \mathrm{ml}$ in NTS for 15 min at room temperature. Unbound FITC-Con A was removed by extensive washing with NTS. After various incubation times (30-120 min), preparations were investigated for cap formation using a Leitz Orthoplan fluorescence microscope. For cytochalasin D (CD) treat- ment, dissociated cells were incubated with $\mathrm{CD}(1 \mathrm{mg} /$ $\mathrm{ml}$ stock solution in dimethyl sulfoxide) at $10 \mu \mathrm{g} / \mathrm{ml}$ for $15 \mathrm{~min}$ at room temperature. Subsequently cells were labeled with the lectin, incubated for another $60 \mathrm{~min}$ in the presence of $\mathrm{CD}$, and then rapidly washed and investigated.

For fluorescence photobleaching recovery measurements, dissociated cells were labeled either with the fluorescent lipid analogue HEDAF (15 min at $80 \mu \mathrm{g}$ / $\mathrm{ml}$ ), or with rhodamine-labeled succinylated concanavalin A (RS-ConA; $15 \mathrm{~min}$ at $40 \mu \mathrm{g} / \mathrm{ml}$ ), in a manner similar to that described above.

\section{Fluorescence Photobleaching Recovery Measurements}

Lateral mobility characteristics of membrane lipids and proteins were measured, using the FPR technique as described before (Axelrod et al, 1976; Koppel et al, 1976). The fluorescent probe molecules in the cell plasma membrane were excitated with a laser beam (argon ion laser, Coherent (R-4) in the Gaussian mode at $488 \mathrm{~nm}$ for HEDAF and $514 \mathrm{~nm}$ for RS-Con A, focused with a Leitz $100 \times / 1.2$ Phaco water objective (unless stated otherwise). Spot sizes were calibrated by scanning a fluorescent glass capillary through the laser beam at a known velocity (L. G. J. Tertoolen, unpublished). Excitation before bleaching was performed with an attenuated laser beam, giving rise to a power of $2-5 \mathrm{~W} / \mathrm{cm}^{2}$ in the plane of the membrane. Bleaching was performed by a short (20-60 msec) 2500 -fold increase in laser intensity, resulting in 40-60\% bleaching of the fluorescence in the illuminated area. Details of the equipment used, have been described earlier (Boonstra et al, 1982; Dictus et al., 1984). Diffusion coefficients and mobile fractions were determined graphically from the kinetics of recovery according to the method of Axelrod et al (1976). All measurements were carried out at room temperature, using double-concentrated NTS to diminish cell surface movements.

\section{Chemicals}

FITC-Con A was obtained from IBF (Paris, France), rhodamine labeled succinylated Con A from EY Laboratories (San Mateo, Calif.), cytochalasin D from Aldrich (Milwaukee, Wisc.), and HEDAF from Molecular Probes (Plano, Tex.).

\section{RESULTS}

\section{Lectin Binding (FITC-Con A) to Dissociated Cells of $X$. laevis Embryos}

We have extended the observations of Johnson and Smith (1977) by investigating capping phenomena of FITC-Con A in $X$ laevis dissociated cells, as a function 
of time during various developmental stages. Representative fluorescence and transmission photographs 30 min after incubation with FITC-Con A are shown in Fig. 1.

Morula cells (stage 6) show only very little FITC-Con A binding. The external surface of the cells facing the perivitellin space is actually devoid of fluorescence. More intense Con A binding is only observed at the level of cellular boundaries when the blastomeres are not com- pletely dissociated (data not shown). A large increase in Con A binding is observed on passing from morula to blastula cells. Immediately after labeling, early blastula cells (stage 7) show uniform fluorescence on the entire cell surface. With time, however, the fluorescence becomes increasingly heterogeneous. Hardly any patches are seen $30 \mathrm{~min}$ after labeling (Fig. 1A), in agreement with the observation of Johnson and Smith (1977). However, patching becomes more intense after $1 \mathrm{hr}$, while
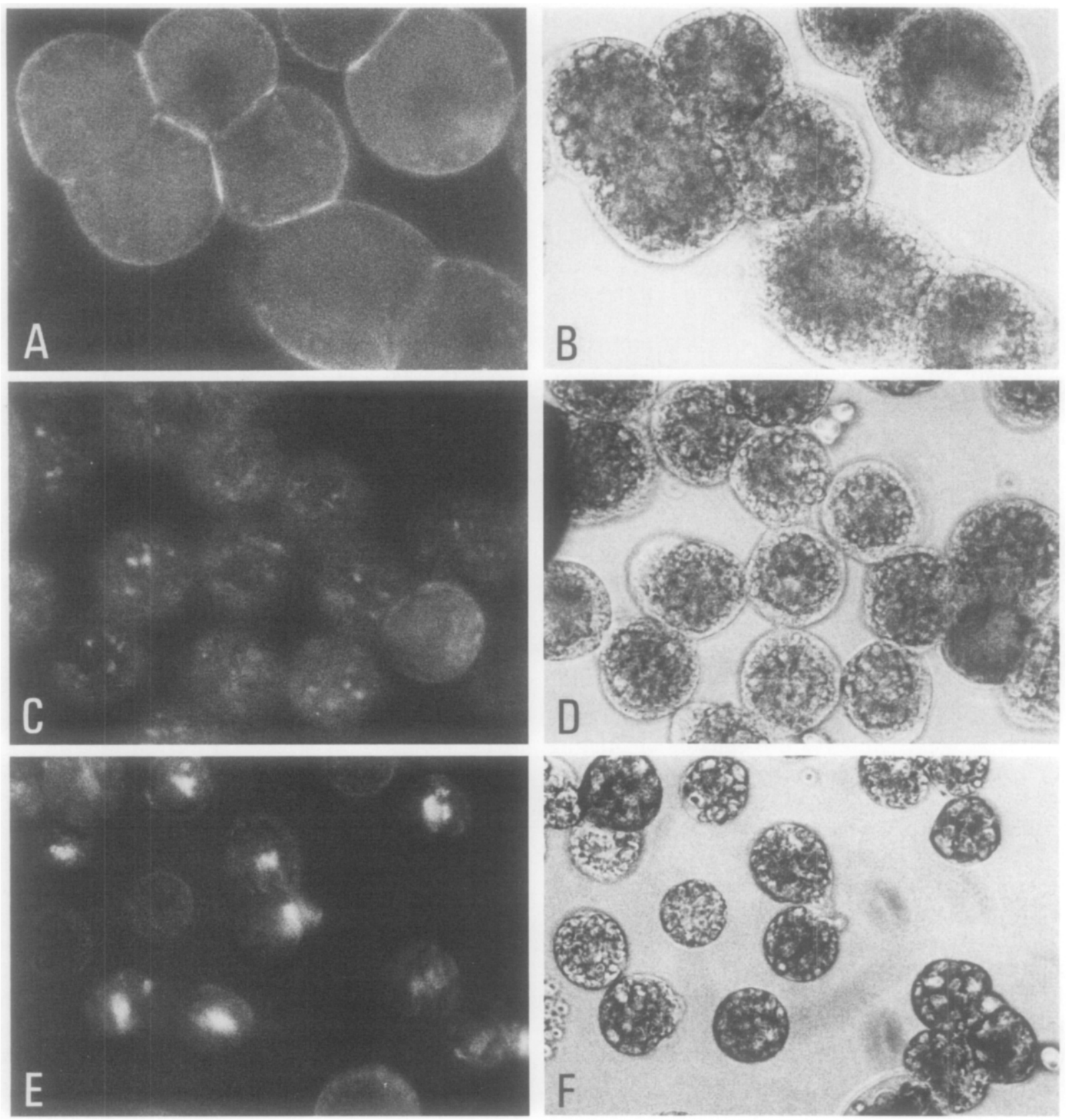

FIG. 1. Fluorescence and phase-contrast photographs of dissociated cells from Xenopus laevis embryos at various developmental stages. Cells were labeled with FITC-Con A as described in the text, and photographed 30 min after removal of the lectin. Magnification $\times 375$. (A, B) Early blastula cells (stage 7); (C, D) midgastrula cells (stage 10); (E, F) early neurula cells (stage 13). 

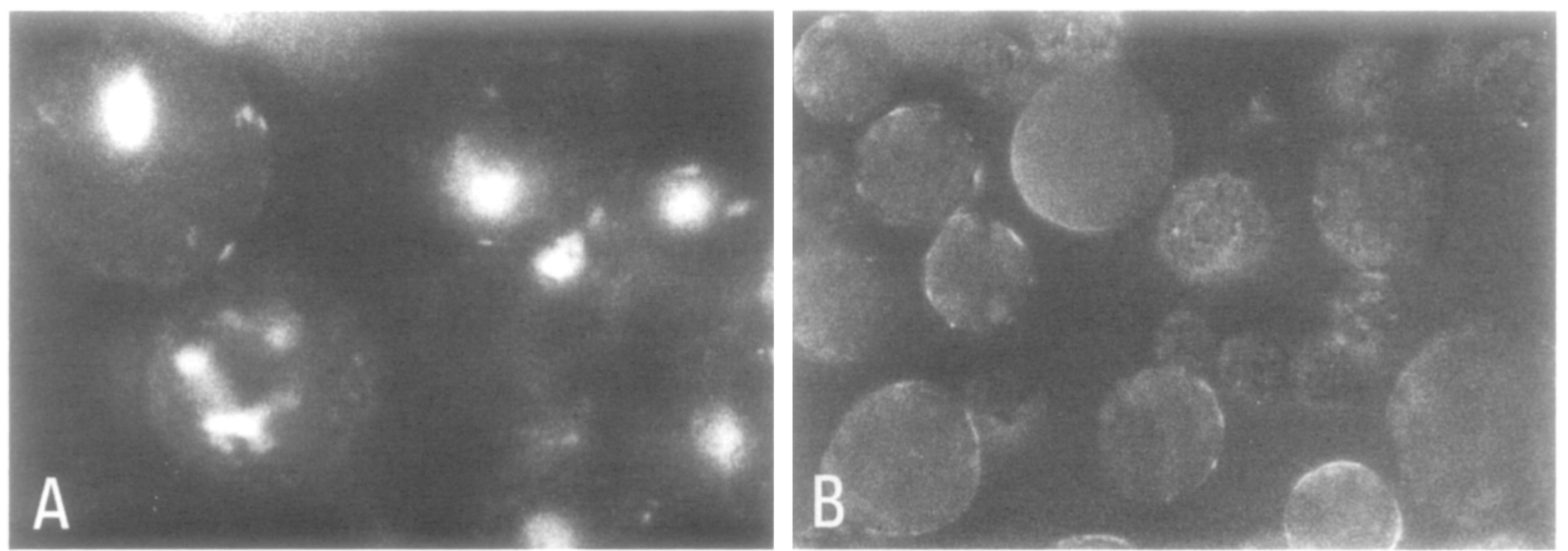

FIG. 2. Fluorescence and phase-contrast photographs of dissociated cells from Xenopus laevis embryos. Magnification $\times 375$. (A) Early blastula cells (stage 7) $2 \mathrm{hr}$ after labeling with FITC-Con A. (B) Early neurula cells (stage 13), pretreated with cytochalasin D, 1 hr after treatment with FITC-Con A.

$2 \mathrm{hr}$ after labeling capping is prominent for the great majority of cells (see Fig. 2A). With respect to cell motility at blastula stage, no lobopodial activity is observed among dissociated cells in control or FITC-Con A-treated cells incubated in NTS (Fig. 1B).

Midgastrula cells (stage 10) show abundant patching and even some capping $30 \mathrm{~min}$ after incubation with FITC-Con A (Fig. 1C), in agreement with the observation of Johnson and Smith (1977). After $1 \mathrm{hr}$ a cap is present in the great majority of cells (not shown). Dissociated gastrula cells show active lobopodial movement which does not seem to be disturbed by the lectin binding (Fig. 1D).

Early neurula cells (stage 13) show abundant capping 30 min after incubation (Fig. 1E). Capping is observed, particularly, on those cells which also show lobopodial activity (Fig. 1F). No further changes are observed upon longer incubation.

In summary, dissociated blastula, gastrula, and neurula cells of $X$ laevis embryos are capable of binding FITC-Con A. The rate of patching and cap formation increases considerably on going from blastula to gastrula and neurula stage. Differences in cap formation, $30 \mathrm{~min}$ after incubation, as shown in Fig. 1, therefore reflect differences in the rate and not in the ability of cap formation. In this respect, our conclusion differs from that of Johnson and Smith (1977).

Treatment of dissociated Xenopus cells with cytochalasin $\mathrm{D}(10 \mu \mathrm{g} / \mathrm{ml})$ completely inhibits cap formation. This is illustrated in Fig. 2B, which shows neurula cells treated for $15 \mathrm{~min}$ with $\mathrm{CD}$, and photographed $1 \mathrm{hr}$ after incubation with FITC-Con A. No cap formation is observed under these conditions. This process is reversible upon removal of the drug from the incubation medium. These observations indicate that microfilaments are involved in Con A-receptor migration during capping in amphibian cells.

\section{Lateral Motility of Con A-Receptor Sites}

Patching and capping of receptor sites require the lateral redistribution of these molecules within the plane of the plasma membrane. In order to establish whether the observed stage-dependent rate of Con A-receptor capping is directly related to the motility properties of the receptor molecules, we have determined by FPR measurements the lateral mobility characteristics of Con A receptors in dissociated cells from Xenopus embryos at various developmental stages between early blastula and early neurula. During an FPR experiment, fluorophores in a small area of the plasma membrane are bleached in an irreversible way by short exposure to a focused, high-intensity laser beam. From the kinetics of fluorescence recovery in this bleached region, a result of lateral mobility of the fluorophores, the twodimensional diffusion coefficient, and the mobile fraction of the labeled component can be determined (Axelrod et al., 1976).

The lateral mobility characteristics of the Con A receptor were determined after labeling with RS-Con A. This derivative is divalent and has therefore less tendency to induce receptor clustering upon binding than the tetravalent FITC-Con A. Under all conditions tested, a homogeneous fluorescence was observed after RS-Con A labeling, which indicates that the Con A-receptor molecules are uniformly distributed over the plasma membrane of dissociated cells from the Xenopus embryo. As before, various developmental stages were compared: early blastula (stage 7), late blastula stage (stage 8), midgastrula (stage 10), and early neurula (stage 13).

At all developmental stages the fluorescence recovery after photobleaching followed two-dimensional diffusion kinetics (Axelrod et al., 1976). As shown in Table 1, a large fraction of the labeled Con A receptors was immobile on the time scale of FPR-measurements, and 
TABLE 1

Lateral Mobility Characteristics of Con A Receptors in Dissoclated CELLS FROM Xenopus EMBRYos ${ }^{a}$

\begin{tabular}{lccc}
\hline Stage of development & $\begin{array}{c}\text { Diffusion coefficient } \\
\left(\mathrm{cm}^{2} / \mathrm{sec} ; \times 10^{10}\right)\end{array}$ & $\begin{array}{c}\text { Mobile fraction } \\
(\%)\end{array}$ & $\begin{array}{c}\text { Number of } \\
\text { experiments }\end{array}$ \\
\hline A. Early blastula (7) & $1.82 \pm 0.36$ & $46.9 \pm 3.7$ & 9 \\
B. Late blastula (8) & $2.59 \pm 0.31$ & $45.2 \pm 2.3$ & 16 \\
C. Mid gastrula (10) & $4.25 \pm 0.31$ & $41.6 \pm 2.3$ & 20 \\
D. Early neurula (13) & $5.25 \pm 0.29$ & $37.9 \pm 1.9$ & 24 \\
\hline
\end{tabular}

a Diffusion coefficients and mobile fractions were estimated from FPR kinetics, after labeling the cells with RS-Con A. Excitation beam $(\lambda=514 \mathrm{~nm})$ was focused through a $100 \times / 1.2$ water objective to a spot with $1 / e^{2}$ radius of 0.81 $\mu \mathrm{m}$. Data are expressed as means \pm SEM.

${ }^{b}$ Including stage number according to Nieuwkoop and Faber (1967).

this fraction increased slightly during development. An analysis of variance (see Snedecor and Cochran, 1967), carried out on the measured mobile fractions, showed that significantly more receptors are immobile at the neurula stage than at early and late blastula stage $(P$ $<0.05$ ). Other statistically significant differences were not observed.

The lateral mobility of the mobile fraction of Con A receptors increased almost threefold during development (see Fig. 3B, Table 1). No significant difference could be detected by an analysis of variance between the diffusion coefficients in early and late blastula cells, whereas the diffusion rate of Con A receptors increased significantly with the onset of gastrulation and further with neurulation. In view of the developmental differences in the rate of capping of Con A receptors induced by FITCCon A, described here, it seems likely that lateral mobility of the receptor molecules within the plasma membrane plays an important role in the process of cap formation. In addition, we conclude that the onset of the morphogenetic gastrulation and neurulation movement in the Xenopus embryo is associated with an increase in membrane protein mobility.

\section{Lateral Mobility of Plasma Membrane Lipids}

Generally, the lateral mobility of membrane proteins may be restricted by the fluidity of the membrane lipid matrix (Singer and Nicolson, 1972) and by interactions with cytoskeletal elements (Schlessinger et al, 1977). We have measured the lateral mobility of plasma membrane lipids in dissociated cells from Xenopus embryos during the relevant period of development, in order to establish the possible involvement of alterations in membrane fluidity in determining the rate of membrane protein mobility.

The fluorescent lipid analog 5-( $N$-hexadecanoyl)aminofluorescein was used as a probe molecule for determining lipid lateral mobility. HEDAF incorporated readily into the plasma membrane, and the cells displayed a homogeneous fluorescence after labeling in all
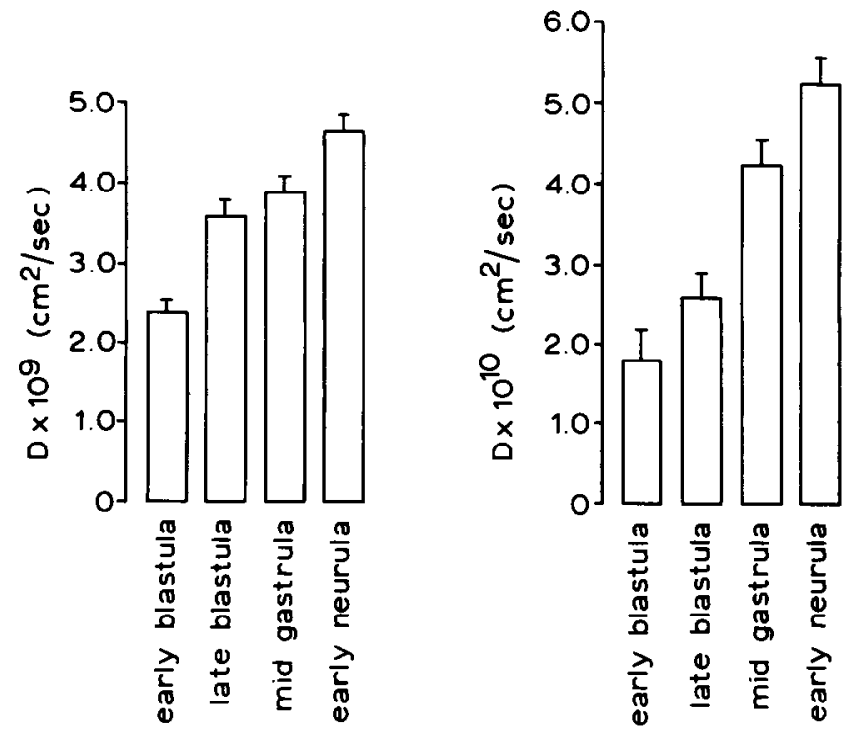

FIG. 3. Lateral diffusion coefficient (D) of HEDAF (A) and RS-Con $A$ receptor $(B)$ in the plasma membrane of dissociated cells from Xenopus laevis embryos at various stages of development. See text for details.

cases. As usual for lipid probes, HEDAF showed typical two-dimensional diffusion kinetics in FPR experiments. From the late blastula stage onward, the fractional recovery or mobile fraction was approximately $80 \%$ and did not change significantly. Incomplete recovery is probably due to some internalization of the probe molecule, in combination with a certain autofluorescence of the underlying cytoplasm which contributes $5-10 \%$ of the total fluorescence intensity. In early blastula cells, however, HEDAF behaved somewhat different in this respect, as can be seen from Table 2 . Not only did we observe a significantly lower fractional recovery $(P$

TABLE 2

Lateral Mobility Characteristics of Plasma Membrane Lipids in Dissociated Cells from Xenopus EmRryos ${ }^{a}$

\begin{tabular}{lccc}
\hline Stage of development & $\begin{array}{c}\text { Diffusion coefficient } \\
\left(\mathrm{cm}^{2} / \mathrm{sec} ; \times 10^{9}\right)\end{array}$ & $\begin{array}{c}\text { Mobile fraction } \\
(\%)\end{array}$ & $\begin{array}{c}\text { Number of } \\
\text { experiments }\end{array}$ \\
\hline A. Early blastula & & & \\
B. Late blastula & $2.39 \pm 0.14$ & $72.5 \pm 4.6$ & 10 \\
1. Ectoderm & $3.61 \pm 0.18$ & $82.3 \pm 1.4$ & 37 \\
2. Mesoderm & $3.86 \pm 0.29$ & $79.0 \pm 2.7$ & 10 \\
3. Endoderm & $3.74 \pm 0.31$ & $80.8 \pm 2.7$ & 11 \\
C. Midgastrula & $3.36 \pm 0.30$ & $85.4 \pm 1.9$ & 16 \\
D. Early neurula & $3.89 \pm 0.19$ & $80.0 \pm 2.0$ & 29 \\
1. Neurectoderm & $4.67 \pm 0.38$ & $81.3 \pm 1.6$ & 27 \\
2. Chordomesoderm & $5.11 \pm 0.43$ & $83.8 \pm 3.1$ & 6 \\
3. Endoderm & $4.62 \pm 0.39$ & $78.9 \pm 3.1$ & 12 \\
\hline
\end{tabular}

${ }^{a}$ Diffusion coefficients and mobile fractions were estimated from FPR kinetics, after labeling the cells with the fluorescent lipid probe HEDAF. Excitation beam $(\lambda=488 \mathrm{~nm})$ was focused through a Leitz $100 \times / 1.2$ water objective to a spot with $1 / e^{2}$ radius of $0.95 \mu \mathrm{m}$. Data are expressed as means $\pm \mathrm{SEM}$.

${ }^{b}$ To avoid the effects of periodic cellular contractions, measurements were performed with a Leitz $32 \times / 0.40$ objective (spot radius $2.65 \mu \mathrm{m}$ ). 
$<0.05$ ), but also the variation among individual cells appeared to be greater at this stage than at others.

The lateral mobility of membrane lipids in dissociated cells, increased approximately two-fold, as development proceeded from the early blastula to the early neurula stage (see Fig. 3A, Table 2). Thus, both the Con A receptors and the plasma membrane lipids become less restricted in their motion during development, but glycoproteins more so than lipids. In addition, there are noticeable differences in the dynamic behavior of these two classes of molecules during development. The diffusion coefficient of membrane lipids increased significantly during development from early to late blastula $(P<0.05)$, but did not show any further change during gastrulation. This is in contrast to the observed modulation in Con A-receptor mobility in this period, and indicates that an alteration in membrane fluidity precedes gastrulation, without an immediate effect on protein mobility. During further development until the early neurula stage, however, lipid and protein lateral mobility both increase significantly $(P<0.05)$, and to a similar extent.

We have also tested for regional differences within the embryo in the lateral mobility of membrane lipids by taking FPR measurements on dissociated cells from the three germ layers at blastula and neurula stage, as indicated in Table 2. No significant differences between the germ layers could be detected. Therefore, we conclude that the observed increase in lateral mobility of membrane lipids with gastrulation and neurulation reflects an overall change in membrane properties within the Xenopus embryos at these stages.

\section{DISCUSSION}

Stimulated by the earlier observations of Johnson and Smith (1977), who described developmental modulations in lectin induced capping of membrane proteins in the Xenopus embryo, we have analyzed, in detail, the possible changes in the dynamic behavior of membrane constituents during early Xenopus development from the blastula until the neurula stage. Indirect evidence for alterations in the mobility of membrane proteins was obtained by studying the rate of tetravalent FITC-Con A-induced patching and capping of Con A-binding glycoproteins. Direct determinations of the mobility characteristics of these glycoproteins were made by FPR measurements on dissociated cells, using divalent rhodamine-conjugated succinylated ConA as a fluorophore. Alterations in the mobility of membrane lipids were determined similarly, using the fluorescent lipid analogue HEDAF as a probe. Our results demonstrate that during this period of development: (i) tetravalent Con A can induce cap formation at all stages, in contrast to divalent Con $\mathrm{A}$; (ii) the rate of cap formation increases with development; (iii) cap formation can be prevented by microfilament-affecting drugs such as cytochalasin $D$; (iv) the rate of increase in the Con A-receptor capping is correlated with an increase in the lateral mobility of the receptor molecules; (v) the lateral mobility of membrane glycoproteins, i.e., Con A receptors, is modulated in part independently from the lateral mobility of membrane lipids; and (vi) the onset of morphogenetic movements is associated with an increase in membrane fluidity, as revealed by the lateral mobility of membrane lipids.

Our observations on the capping of Con A receptors by binding of tetravalent Con A confirm for the greater part those described by Johnson and Smith (1977), but not completely. They contrast with their data in that Con A-receptor patching and capping could also be induced in blastula cells. The difference between the blastula and successive stages of development is a quantitative rather than a qualitative one. In blastula cells the segregation of FITC-Con A into a polar cap takes at least one hour at room temperature, whereas in gastrula and neurula cells cap formation can be seen already within 30 and $15 \mathrm{~min}$, respectively. Besides the large scale segregation of membrane proteins involved in cap formation, the rate of initial patching of receptors also increased with development. These results suggest that the lateral mobility of the Con A-receptor molecules becomes gradually less restricted over this period.

As in other systems (Nicolson, 1976), microfilament structures are involved in the active migration of Con A receptors in embryonic amphibian cells, as evidenced by the inhibiting effect of cytochalasin $D$ on patching and capping. Others have shown that the polar segregation of surface receptors is associated with cocapping of microfilaments (Albertini, 1977a,b). Singer et al. (1978) have suggested that this is a two-step process: the binding of a multivalent ligand to the cell surface produces the anchorage of protein patches to underlying cytoskeletal structures, whereupon microfilaments are responsible for the active migration of the aggregated proteins toward the cap region. In our experiments, however, cytochalasin $\mathrm{D}$ also prevented the formation of visible patches, which suggests that microfilaments are also involved in the initial stages of receptor aggregation, unless the appearance of visible patches represents already an advanced stage of the process.

As microfilaments certainly play a prominent role in receptor segregation, the observed increase in the rate of capping during Xenopus development could rely on changes in the organization of the cytoskeleton. The FPR measurements provide some evidence hereto, in that the mobile fraction of Con $A$ receptors decreased with development. This could indicate that the transmembrane linkage between membrane proteins and cytoskeleton is changed. 
The direct determination of Con A-receptor mobility, using RS-Con A as a fluorescent ligand, demonstrates that the developmental change in the rate of capping is associated with an increase in the lateral diffusion coefficient of the mobile receptors. This suggests that a direct correlation exists between the lateral mobility of those receptors and the induction of patching and capping. We have extended the observations of Johnson and Smith (1977) by using Con A as a probe for relating capping phenomena to lateral mobility characteristics of membrane proteins. At this stage of research, however, no data are available on the nature and number of Con A receptors on dissociated cells of $X$ laevis embryos at the various developmental stages. From the diffusion coefficient of the Con A receptors in relation to that of the membrane lipids, it can be concluded that glycolipids will not contribute significantly to the number of receptors. The chemical nature of the immobile fraction of Con A receptors at the time scale of the FPR measurements remains obscure, although interactions with cytoskeletal proteins seem likely in the light of previous studies (Schlessinger et al., 1977; Edidin, 1981). It will be of interest to study to what extent this immobile fraction participates in patching and capping phenomena.

Protein lateral mobility can be limited by transmembrane anchorage to cytoskeletal proteins or by membrane lipid fluidity. The measurements on lipid mobility, using HEDAF as a probe, show a twofold increase in lateral diffusion coefficient during development from blastula till neurula stage. Since lipid lateral diffusion is not very sensitive to gross compositional or structural changes in the membrane (Cherry, 1979; Peters, 1981), this may reflect a major compositional change during development which could give rise to large alterations in the biochemical properties of the membrane. It is important to stress, however, that the lateral mobilities of proteins and lipids are not fully modulated in parallel. This indicates that protein and lipid mobility are indeed, at least in part, subject to different control mechanisms, as found also in other systems (de Laat et al, 1980, 1983).

Two interesting aspects of the data on membrane lipid mobility should be noted. First, a slightly lower mobile fraction of HEDAF molecules was found in early blastula cells as compared to cells from later stages. In a recent study from this laboratory, on possible regional differences in the mobility properties of membrane lipids in the unfertilized and fertilized Xenopus, it was shown that plasma membrane lipids show only fractional recovery after photobleaching before fertilization, the mobile fraction having a fivefold larger lateral diffusion coefficient at the vegetal side than at the animal side of the egg. Probably as a result of the fusion of cortical granules, fertilization leads to complete immobilization of membrane lipids in the animal plasma membrane, while only a slight reduction in their mobility was found at the vegetal side. The plasma membrane of the fertilized Xenopus egg thus consists of two macrodomains, with a sharp transition at the equatorial zone (Dictus et al., 1984). The dissociated cells used in the present study obviously expose for the greater part newly formed membranes, localized in situ in the inside of the embryo. It is an interesting possibility that the reduction in mobile fraction in early blastula cells is a reflection of the redistribution of the original animal plasma membrane over the cells generated in early development.

The second important aspect of these data concerns the finding that lipid mobility rapidly increases as the embryo prepares itself for gastrulation, i.e., at the transition from early to late blastula stage. As mentioned, it is just at this period of development that the mobility properties of the cells alter drastically, as observed readily by the acquired ability of late blastula cells to produce lobopodia and so-called circus movements (Holtfreter, 1946; Satoh et al., 1976). It is believed that this ability is an expression of enhanced cell motility and cell deformability, functional in accomplishing gastrulation movements. Recently, Newport and Kirschner (1982) have shown that dissociated cells of $X$ laevis acquire the capability to form lobopodia at the so-called midblastula transition. It is our experience, however, that lobopodia formation at late blastula stage can only be observed if cell dissociation is performed at an enhanced ionic strength (M. Gadenne, R. Tencer; unpublished).

In conclusion it seems that the capability of dissociated cells to form lobopodia is a necessary, although most likely not a sufficient condition to permit cellular movement in the embryo. The observed increase in membrane fluidity may favor cell surface deformability and thereby set necessary conditions for the onset of gastrulation. In fact, preliminary experiments by one of us (M.G.) in which early blastula cells, generally not showing lobopodia formation, were treated with the local anesthetic lidocaine, suggest a causal relationship between increased membrane fluidity and cell motility combined with surface deformability, as this fluidizing treatment rapidly induced lobopodia formation. It is interesting to note that these local anesthetics may also affect cytoskeleton interactions (Poste et al., 1975).

Taken together, the data presented in this study demonstrate that during early Xenopus development the mobility of membrane proteins and lipids increases significantly. Most likely, the observed increase in the rate of capping of Con A receptors in dissociated cells, obtained from successive developmental stages between early blastula and early neurula is directly related to the increased lateral mobility of these receptors. In part, this parallels the associated changes in membrane lipid fluidity which are limited to initiation of morphogenetic 
cell movements during development. It will be of interest to study further consequences of the observed plasma membrane alterations for the control of early amphibian development.

The present experiments were carried out, in part, during a stay of M.G. at the Hubrecht Laboratory, made possible by a short fellowship from EMBO and the Fond National de la Recherche Scientifique. We thank Mr. L. G. J. Tertoolen for technical assistance.

\section{REFERENCES}

AI,Rertini, D. F., and ANDERson, E. (1977a). Microtubule and microfilament rearrangements during capping of concanavalin $A$ receptors on cultured ovarian granulosa cells. J. Cell Biol. 73, 111-127.

Albertini, D. F., Berlin, R. D., and Oliver, J. M. (1977b). The mechanism of concanavalin A cap formation in leukocytes. J. Cell. Sci. 26, 57-75.

AXelrod, D., KopPEl, D. E., Schlessinger, J., Elson, E., and WEBb, W. W. (1976). Mobility measurements by analysis of fluorescence photobleaching recovery kinetics. Biophys. $J$. 16, 1055-1069.

Boonstra, J., Nelemans, S. A., FeiJen, A., Bierman, A., van Zoelen, E. J. J., VAN DER SAAG, P. T., and DE LAAT, S. W. (1982). Effect of fatty acids on plasma membrane lipid dynamics and cation permeability in neuroblastoma cells. Biochim. Biophys. Acta 692, 321329.

Cherry, R. J. (1979). Rotational and lateral diffusion of membrane proteins. Biochim. Biophys. Acta 559, 289-327.

DE LAAT, S. W., VAN DER SAAG, P. T., ElSON, E. L., and Schlessinger, J. (1980). Lateral diffusion of membrane lipids and proteins during the cell cycle of neuroblastoma cells. Proc. Natl. Acad. Sci. USA 77, 1526-1528.

DE LAat, S. W., Tertoolen, L. G. J., VAn DER SAaG, P. T., and Bluemink, J. G. (1983). Quantitative analysis of modulations in numerical and lateral distribution of intramembrane particles during the cell cycle of neuroblastoma cells. J. Cell Biol 96, 1047-1055.

Dictus, W. J. A. G., van Zoelen, E. J. J., Tetteroo, P. A. T., Tertoolen, L. G. J., DE LAAT, S. W., and BLUEMINK, J. G. (1984). Lateral mobility of plasma membrane lipids in Xenopus eggs; regional differences related to animal/vegetal polarity become extreme upon fertilization. Dev. Biol. 101, 201-211.

EDIDIN, M. (1981). Molecular motions and membrane organization and function. In "Membrane Structure, New Comprehensive Biochemistry" (J. B. Finean and R. H. Michell, eds.), Vol. 1, pp. 37-82. Elsevier/ North-Holland, Amsterdam.

HOLTFRETER, J. (1946). Structure, motility and locomotion in isolated embryonic amphibian cells. J. Morphol 79, 27-62.

JoHNSON, K. E. (1969). Altered contact behavior of presumptive mesodermal cells from hybrid amphibian embryos arrested at gastrulation. J. Exp. Zool. 170, 325-332.

JoHNSON, K. E. (1970). The role of changes in cell contact behaviour in amphibian gastrulation. J. Exp. Zool 175, 391-428.

JoHnson, K. E. (1972). The extent of cell contact and the relative frequency of small and large gaps between presumptive mesodermal cells in normal gastrulae of Rana pipiens and the arrested gastrulae of the Rana pipiens $9 \times$ Rana catesbeiana $\delta$ hybrid. J. Exp. Zool. 179, 227-238.

JoHNSON, K. E., and Smiтh, E. P. (1977). Lectin binding to dissociated cells from two species of Xenopus embryos. Cell Differ. 5, 301-309.

KopPEL, D. E., AXELROD, D., SCHLESSINGER, J., ELSON, E. L., and WEBB, W. W. (1976). Dynamics of fluorescence marker concentration as a probe of mobility. Biophys. J. 16, 1315-1329.

MACMURDO-HARRIS, H., and ZALIK, S. E. (1971). Microelectrophoresis of early amphibian embryonic cells. Dev. Biol 24, 335-347.

NAKATSUJ, N. (1976). Studies on the gastrulation of amphibian embryos; ultrastructure of the migrating cells of anurans. Wilhelm Roux's Arch. Dev. Biol. 180, 229-240.

NEWPORT, J., and KIRSCHNER, M. (1982). A major developmental transition in early Xenopus embryos: Characterization and timing of cellular changes at the midblastula stage. Cell 30,675-686.

Nicolson, G. L. (1976). Transmembrane control of the receptors on normal and tumor cells. Cytoplasmic influence over cell surface components. Biochim. Biophys. Acta 457, 57-108.

NiEUwKoop, P. D., and FABER, J. (1967). "Normal Table of Xenopus laevis (Daudin)," 2nd ed. North-Holland, Amsterdam.

NIU, M. C., and TwITTY, V. C. (1953). The differentiation of gastrula ectoderm in medium conditioned by axial mesoderm. Proc. Natl. Acad. Sci. USA 39, 985-989.

Peters, R. (1981). Translational diffusion in the plasma membrane of single cells as studied by fluorescence microphotolysis. Cell Biol. Int. Rep. 5. 733-760.

Poste, G., Papahadjopoulos, D., Jacobson, K., and VAIL, W. J. (1975). The effect of local anesthetics on membrane properties II: Enhancement of the susceptibility of mammalian cells to agglutination by plant lectins. Biochim. Biophys. Acta 394, 520-539.

Satoh, N., Kageyama, T., and Sirakami, K. I. (1976). Mobility of dissociated embryonic cells in Xenopus laevis: Its significance to morphogenetic movement. Dev. Growth Differ. 18, 55-67.

Schlessinger, J., AxelroD, D., KopPel, D. E., WebB, W. W., and ELSON, E. L. (1977). Lateral transport of a lipid probe and labelled proteins on a cell membrane. Science 195, 307-309.

Shaeffer, B. E., Shaeffer, H. E., and BrICK, I. (1973). Cell electrophoresis of amphibian blastula and gastrula cells: The relationship of surface charge and morphogenetic movements. Dev. Biol 34, 6676.

Singer, S. J., and Nicolson, G. L. (1972). The fluid mosaic model of the structure of cell membranes. Science 175, 720-731.

Singer, S. J., Ash, J. F., Bourguignon, L. Y. W., Hegeness, M. H., and Low ARD, D. (1978). Transmembrane interactions and the mechanisme of transport of proteins across membrane. J. Supramol. Struct. 9, 373-389.

SNEDECOR, G. W., and CochraN, W. G. (1967). "Statistical Methods," 6th ed. Iowa State Univ. Press, Ames.

TICKLE, C. A., and TRINKAUS, J. P. (1973). Change in surface extensibility of Fundulus deep cells during early development. J. Cell Sci. 13, 721-726.

TICKLE, C. A., and TRINKAUS, J. P. (1977). Some clues at the formation of protrusions by Fundulus deep cells. J. Cell Sci. 26, 139-150.

WOLF, D. P. (1974). On the contents of cortical granules from Xenopus laevis. Dev. Biol 38, 14-29. 